\title{
DAMPAK SUBSIDI SOLAR TERHADAP KEBERLANJUTAN USAHA PERIKANAN TANGKAP DI BITUNG DAN PELABUHANRATU
}

\author{
Estu Sri Luhur dan Yesi Dewita Sari \\ ${ }^{2}$ Balai Besar Penelitian Sosial Ekonomi Kelautan dan Perikanan \\ JI. KS. Tubun Petamburan VI Jakarta 10260 \\ Telp. (021) 53650162, Fax. (021)53650159 \\ Email: s2luhur@yahoo.com
}

Diterima 21 Februari 2012 - Disetujui 3 Desember 2012

\begin{abstract}
ABSTRAK
Penelitian ini bertujuan untuk mengkaji peranan subsidi harga solar terhadap keberlanjutan usaha perikanan tangkap. Penelitian dilakukan pada tahun 2010 di dua lokasi dengan tingkat pemanfaatan sumber daya perikanan yang berbeda, yaitu Bitung dan Palabuhanratu. Data yang digunakan terdiri dari data primer dan data sekunder. Data primer diperoleh melalui wawancara kepada nelayan yang menggunakan alat tangkap berbeda di kedua lokasi penelitian, kemudian dianalisis dengan menggunakan regresi linier berganda. Hasil penelitian menunjukkan bahwa adanya subsidi harga solar menyebabkan semakin besar keuntungan yang diterima oleh nelayan karena biaya operasional yang ditanggung oleh nelayan semakin rendah. Di Bitung hasil analisis menunjukkan bahwa variabel dummy (D) berpengaruh signifikan terhadap penerimaan sebesar 2,28 yang artinya bahwa pemberian subsidi solar kepada nelayan dapat meningkatkan penerimaan sebesar 2,28\%. Dengan demikian, subsidi solar mampu mendorong usaha perikanan tangkap nelayan di Bitung secara berkelanjutan. Sementara itu di Palabuhanratu menunjukkan bahwa jumlah hari melaut (trip) dan subsidi solar (D) berpengaruh negatif terhadap penerimaan. Makin lama hari melaut di fishing ground Teluk Palabuhanratu justru mengurangi penerimaan nelayan. Hasil ini menunjukkan bahwa pemanfaatan sumber daya perikanan di Teluk Palabuhanratu terindikasi adanya kelebihan upaya penangkapan sehingga subsidi yang diberikan seharusnya bertujuan memfasilitasi nelayan untuk menangkap di luar Teluk Palabuhanratu.
\end{abstract}

Kata Kunci: subsidi perikanan, harga solar, biaya operasional, keberlanjutan usaha, perikanan tangkap

\section{Abstract: Role of Price Subsidies on Diesel Fuel to Sustainability of Fishing Effort in Bitung, North Sulawesi and Palabuhanratu, West Java by Estu Sri Luhur and Yesi Dewita Sari.}

This study aims to assess the role of price subsidies on diesel fuel to the sustainability of fishing. Research was carried out at two locations of Bitung and Palabuhanratu representing different level of fishery resources utilization in 2010. Data used consists of primary and secondary data. Primary data were obtained through interviews with fishers using different gear on both sites and then analyzed using multiple regression. Results showed that diesel price subsidies causes the greater benefits received by the fishermen because the operational costs incurred by the fishermen are getting lower. In Bitung result of the analysis shows that the dummy variable $(D)$ significant on revenue of 2.28 which means that the provision of diesel subsidies for fishermen to increase their revenue to $2.28 \%$. Thus, the diesel subsidies could encourage fishermen fishing effort in Bitung in a sustainable manner. Meanwhile, in the Palabuhanratu result showed that number of days at sea (trip) and diesel subsidies (D) have negative effect to the revenue. The longer days at sea in the fishing ground Palabuhanratu Bay instead reduce fishing revenue. It means, utilization 
of fishery resources in the Palabuhanratu Bay have indicated on excess fishing effort, so that subsidy given should be aimed at facilitating fisher to fishing outside the Palabuhanratu Bay.

Keywords: fisheries subsidies, diesel fuel, operational cost, sustainable business, fishing effort

\section{PENDAHULUAN}

Peningkatan produksi usaha perikanan tangkap laut didorong oleh berbagai kebijakan yang bersifat sektoral dan nasional. Kebijakan sektoral merupakan kebijakan yang dirancang oleh sektor perikanan untuk memanfaatkan potensi sumber daya perikanan yang ada. Sementara itu, kebijakan nasional berupa kebijakan moneter atau fiskal yang dirancang untuk mendorong berkembangnya usaha perikanan. Kebijakan moneter dan fiskal yang dimaksud adalah berupa kredit dan subsidi yang diberikan pemerintah untuk usaha perikanan tersebut.

Salah satu kebijakan fiskal yang diambil pemerintah Indonesia adalah pemberian subsidi, baik langsung maupun tidak langsung kepada nelayan dan petani pembudidaya ikan. Menurut Kamus Oxford (Anonim, 2010), subsidi diartikan sebagai "a sum of money granted from public funds to help an industry or business keep the price of a commodity or service low." Batasan definisi ini sangat sempit sebab konsesi pajak kini juga dilakukan oleh pemerintah dan sering didefinisikan sebagai subsidi. Menurut WTO dalam Agreement on Subsidies and Countervailing Measures (ASCM), subsidi terjadi apabila ada bantuan finansial dari pemerintah kepada lembaga publik yang berada di wilayah negara tersebut. Bentukbentuk bantuan finansial tersebut dapat dibedakan menjadi empat, yaitu bantuan uang langsung, insentif fiskal seperti potongan pajak, bantuan penyediaan barang atau jasa selain infrastruktur atau pembelian barang dan membayarkan beban yang harus dibayar badan-badan privat (WTO, 2006).

Dalam konteks perdagangan bebas, subsidi dianggap menyebabkan distorsi perdagangan karena adanya campur tangan pemerintah yang menguntungkan pihak tertentu. Subsidi juga dianggap berdampak negatif bagi kehidupan masyarakat pesisir, seperti kemiskinan dan degradasi sumber daya yang pada gilirannnya menyebabkan pengangguran. Pemikiran ini yang membuat WTO sebagai organisasi perdagangan dunia menginginkan subsidi, termasuk subsidi perikanan harus dikurangi (phasing out). Bahkan, pengaturan subsidi telah disepakati dalam Agreement on Subsidy and Countervailing Measurement (ASCM) oleh negara-negara yang tergabung dalam WTO yang masih terus dibahas dan nantinya akan disahkan untuk melengkapi teks legal dari ASCM (Satria et al., 2009).

Akan tetapi, subsidi perikanan masih sangat diperlukan oleh pelaku produksi perikanan, seperti nelayan dan pembudidaya. Menurut Schrank and Kiethly Jr. (1999), subsidi perikanan tersebut memperlihatkan dua dampak, yaitu terhadap distribusi pendapatan serta terhadap keberlanjutan sumber daya dan usaha. Dampak yang kedua umumnya terdapat pada sektor perikanan (Milazzo, 1998) dalam hal mendorong peningkatan kapasitas penangkapan ikan; namun jika tidak dikendalikan akan mengancam keberlanjutan usaha dan mendorong deplesi sumber daya.

Selama ini subsidi yang telah diberikan, baik oleh pemerintah maupun pihak swasta kepada pelaku produksi perikanan masih berupa subsidi untuk input produksi perikanan, baik bersifat langsung maupun tidak langsung. Pada usaha perikanan tangkap, subsidi langsung yang sangat dirasakan manfaatnya bagi nelayan adalah subsidi bahan bakar solar yang tertuang dalam Peraturan Presiden (Perpres) No. 9 Tahun 2006. Peraturan ini mengatur tentang pemberian subsidi BBM kepada nelayan dan petani pembudidaya ikan untuk kapal berbobot 30 gross ton (GT) dengan jumlah 
BBM sebanyak 25 kilo liter (KL) per bulan. Penyaluran subsidi solar ini didukung oleh prasarana penyaluran BBM yang dibangun pada pusat-pusat pendaratan ikan dalam bentuk Solar Packed Dealer Nelayan (SPDN), Stasiun Pengisian Bahan Bakar Bersubsidi (SPBB), dan Stasiun Pengisian Bahan Bakar Nelayan (SPBN). Penelitian ini bertujuan untuk mengkaji dampak subsidi solar terhadap keberlanjutan usaha perikanan tangkap di Bitung, Sulawesi Utara dan Palabuhanratu, Jawa Barat.

\section{METODOLOGI PENELITIAN}

\section{Lokasi dan Waktu Penelitian}

Penelitian dilakukan di dua lokasi, yaitu Kota Bitung, Sulawesi Utara dan Kecamatan Palabuhanratu, Jawa Barat. Kedua lokasi tersebut dipilih karena kegiatan penangkapan di Bitung dan Palabuhanratu sangat berbeda. Kegiatan penangkapan di Bitung lebih bersifat offshore karena wilayah penangkapan nelayan sampai ke Laut Arafura dan Laut Sulawesi. Sementara itu, kegiatan penangkapan di Palabuhanratu bersifat onshore karena wilayah penangkapannya terbatas di dalam Teluk Palabuhanratu. Untuk itu, kedua lokasi dapat merepresentasikan bagaimana peranan subsidi solar terhadap kegiatan penangkapan. Penelitian dilaksanakan mulai bulan April sampai dengan November 2010.

\section{Jenis, Sumber, dan Cara Pengumpulan Data}

Jenis data yang dikumpulkan oleh penelitian ini adalah data sekunder dan data primer. Data sekunder meliputi berbagai dokumen, laporan, dan publikasi lainnya yang terkait dengan kebutuhan informasi subsidi, seperti laporan tahunan, data Badan Pusat Statistik, statistik dari Dinas Kelautan dan Perikanan terkait, serta hasil penelitian yang ada terkait dengan subsidi harga solar.

Data primer adalah terkait dengan informasi tentang aktivitas usaha perikanan. Pengumpulan data primer dilakukan dengan cara pengamatan lapangan, wawancara individual mendalam dengan key informan, wawancara dengan menggunakan kuesioner terhadap responden nelayan pada lokasi penelitian. Data primer juga diperoleh melalui diskusi informal dengan beberapa nara sumber yang mempunyai pengetahuan dengan usaha perikanan.

Pengumpulan data primer dilakukan dengan melakukan wawancara terhadap nelayan. Responden terdiri atas 75 responden yang dipilih dengan menggunakan metode purposive sampling berdasarkan jenis alat tangkap. Adapun jumlah responden berdasarkan alat tangkap adalah 13 nelayan bagan, 5 nelayan gillnet, 6 nelayan longline, 16 nelayan pancing tonda, 10 nelayan pole and line, 10 nelayan purse seine, dan 15 nelayan tuna hand line. Namun demikian, pada analisis lebih lanjut penulis menggunakan katagori armada yang ditentukan oleh ukuran tonase kapal.

\section{Metode Analisis Data}

Analisis data dilakukan dengan statistik sederhana untuk mendapatkan gambaran kondisi usaha perikanan dengan subsidi dan kondisi usaha tanpa subsidi. Selain itu juga dilakukan analisis regresi linier berganda untuk mengetahui pengaruh subsidi terhadap usaha perikanan tangkap dengan menggunakan variabel dummy.

Usaha perikanan tangkap ditinjau dari besarnya penerimaan usaha yang dapat diperoleh oleh nelayan untuk setiap trip penangkapan. Usaha perikanan tangkap dipengaruhi oleh beberapa faktor atau variabel, antara lain jumlah hari melaut, jumlah ABK, dan besarnya biaya operasional yang digunakan. Model yang digunakan untuk mengetahui faktor-faktor yang mempengaruhi usaha perikanan tangkap tersebut adalah sebagai berikut:

$\operatorname{Ln} Y=\beta_{0}+\beta_{1} \operatorname{Ln} X_{1}+\beta_{2} \operatorname{Ln} X_{2}+\beta_{3} \operatorname{Ln} X_{3}+\beta_{4} D+e$

Keterangan:

$\mathrm{Y}=$ Penerimaan nelayan/Revenue of fisher (Rp/trip)

$\beta_{\mathrm{o}}=$ Intersep $/$ Intercept 
$\beta_{1}-\beta_{5}=$ Koefisien/Coefficient

$X_{1}=$ Jumlah hari melaut/Day sea trip (day/ trip)

$X_{2} \quad$ = Jumlah ABK/Crew of boat (people) trip)

$X_{3}=$ Jumlah biaya operasional/Operational costs (Rp/trip)

$D \quad=$ Dummy $(1=$ menerima subsidi, $0=$ tidak menerima subsidi)/Dummy (1 = received subsidy, $0=$ unreceived)

Asumsi dalam analisis regresi linier berganda adalah sebagai berikut.

1. Sisaan mempunyai ragam homogen

Asumsi ini berimplikasi bahwa setiap pengamatan pada peubah respon mengandung informasi yang sama penting. Konsekuensinya, semua pengamatan di dalam metode kuadrat terkecil mendapatkan bobot yang sama besar. Dengan kata lain, ketidakhomogenan ragam mengakibatkan beberapa pengamatan mengandung informasi yang lebih dibandingkan yang lain. Dengan demikian, pengamatan ini seharusnya mendapatkan bobot yang lebih besar dibandingkan pengamatan yang lain.

2. Sisaan saling bebas

Sisaan yang tidak saling bebas atau sisaan berkorelasi mungkin disebabkan oleh beberapa hal. Data yang dikumpulkan berdasarkan urutan waktu tertentu seringkali memiliki sisaan saling berkorelasi. Sisaan dari pengamatan pada waktu tertentu cenderung untuk berkorelasi dengan sisaan yang berdekatan. Pengaruh adanya sisaan yang saling berkorelasi adalah berkurangnya presisi penduga metode kuadrat terkecil, serupa dengan pengaruh ketidakhomogenan ragam.

3. Sisaan menyebar normal

Penduga dengan metode kuadrat terkecil tetap merupakan penduga tak bias terbaik apabila asumsi lain terpenuhi. Kenormalan hanya diperlukan pada waktu pengujian hipotesis dan penyusunan selang kepercayaan bagi parameter. Secara umum, pengaruh ketidaknormalan sisaan terhadap pengujian dan penyusunan selang kepercayaan adalah bahwa taraf nyata yang berkaitan dengan dua hal tersebut tidak lagi sesuai dengan yang ditentukan.

4. Tidak ada masalah multicolinearity antar peubah bebas

Analisis regresi berganda mensyaratkan bahwa antar peubah penjelas tidak boleh ada hubungan linier. Efek dari adanya ragam yang besar adalah adanya nilai dugaan yang menjadi aneh dan beberapa peubah penjelas dinyatakan tidak signifikan.

Koefisien determinasi $\left(R^{2}\right)$ dalam hasil regresi menunjukkan suatu nilai yang menerangkan besarnya keragaman dalam peubah tak bebas yang dapat dijelaskan oleh peubah bebas, yang umumnya dinyatakan dalam persentase (\%). Sementara itu, P-value, menunjukkan peluang bagi penerimaan $\mathrm{H}_{0}$ dalam pengujian koefisien regresi. Apabila nilai $P$ tersebut lebih besar dari taraf nyata yang ditetapkan dalam pengujian, maka dikatakan model regresi tersebut tidak nyata, artinya semua koefisien regresi sama dengan nol. Apabila nilai $\mathrm{P}$ tersebut lebih kecil dari taraf nyata yang ditetapkan maka dikatakan model regresi tersebut nyata (Pindyck, 1998).

Estimasi koefisien model dilakukan dengan menggunakan analisis Ordinary Least Square (OLS) terhadap model yang digunakan. Untuk itu, Subsidi dibuatkan dengan variabel dummy, yaitu dummy 1 untuk responden yang menggunakan bahan bakar solar dan dummy 0 untuk nelayan yang menggunakan bahan bakar selain solar. Variabel penerimaan diperoleh dari total jumlah hasil tangkapan dikali dengan harga masing-masing jenis ikan hasil tangkapan. Jumlah hari melaut yang 
digunakan adalah jumlah hari melaut yang dilakukan responden pada saat musim biasa, yaitu bukan pada musim puncak dan juga bukan pada musim paceklik. Jumlah anak buah kapal (ABK) diperoleh dari rata-rata jumlah $A B K$ setiap trip penangkapan. Biaya operasional terdiri dari biaya untuk pembelian bahan bakar, biaya ransum/konsumsi di kapal serta beberapa biaya lainnya yang selalu dikeluarkan untuk setiap trip penangkapan.

Selanjutnya, variabel-variabel tersebut dianalisis dengan menggunakan OLS. Analisis OLS dengan metode semilogarithmic dilakukan untuk variabel penerimaan, jumlah hari melaut, dan jumlah ABK. Analisis OLS dengan metode logarithmic dilakukan untuk variabel ratarata biaya operasional, sedangkan variabel dummy tidak dilakukan secara logarithmic.

\section{HASIL DAN PEMBAHASAN}

\section{Kebijakan Subsidi Perikanan}

Subsidi dalam pengertian ekonomi merupakan transfer finansial dari pemerintah kepada pelaku usaha, sehingga subsidi perikanan diberikan kepada nelayan, pembudidaya, dan pengolah hasil-hasil perikanan. Subsidi perikanan ada yang diberikan secara langsung dan tidak langsung. Subsidi langsung dapat menyebabkan rendahnya biaya operasi penangkapan ikan, sedangkan subsidi tidak langsung dapat mendorong peningkatan kualitas ikan hasil tangkapan karena semakin sempurnanya infrastruktur yang mendukung usaha penangkapan (Zulham, 2008).

Pembelian bahan bakar minyak merupakan salah satu biaya terbesar yang ditanggung oleh nelayan dalam melakukan usaha penangkapan. Solar merupakan bahan bakar utama bagi kapal motor, sedangkan kapal dengan mesin tempel menggunakan bahan bakar campuran bensin dan minyak. Sementara itu, kebijakan pemerintah yang memberikan subsidi bahan bakar minyak hanya berupa solar sehingga nelayan yang melakukan penangkapan dengan menggunakan kapal dengan mesin tempel tidak merasakan efek atau manfaat dari subsidi harga solar. Sebaliknya, subsidi harga solar yang disalurkan melalui stasiun pengisian bahan bakar solar sangat bermanfaat bagi kapal motor dengan tonase lebih besar yang membutuhkan solar lebih banyak.

Pemberian subsidi, termasuk subsidi perikanan, menjadi perdebatan antara negara-negara maju dan berkembang karena dianggap mengganggu jalannya perdagangan bebas yang digaungkan oleh negara-negara maju. Sementara itu, negaranegara berkembang, termasuk Indonesia memandang subsidi perikanan masih sangat diperlukan oleh nelayan di negaranya untuk menjamin keberlanjutan usaha mereka. Untuk itu, pemerintah Indonesia memastikan akan tetap memberikan subsidi perikanan bagi nelayan berskala kecil di sebuah forum menteri kelautan dan perikanan kawasan Asia Pacific Economy Cooperation (APEC) pada tahun 2010 lalu.

Kebijakan subsidi ini diberikan untuk meningkatkan daya saing pelaku usaha perikanan skala kecil sekaligus untuk mengurangi beban ekonomi mereka. Untuk tahun 2010, Kementerian Kelautan dan Perikanan telah mengusulkan alokasi subsidi BBM sebanyak 2.516.976 kiloliter yang terdiri atas 1.955.376 kiloliter per tahun untuk nelayan dan 561.600 kiloliter per tahun untuk pembudidaya ikan skala kecil (Ginanjar, 2010).

\section{Struktur Perikanan di Bitung dan Palabuhanratu}

Kota Bitung dan Kecamatan Palabuhanratu memiliki struktur perikanan yang berbeda jika dilihat dari wilayah penangkapannya (fishing ground), armada penangkapan, dan alat tangkap yang digunakan. Dilihat secara geografis, wilayah penangkapan kedua lokasi penelitian tersebut menunjukkan perbedaan yang cukup signifikan. Nelayan Bitung umumnya menangkap ikan di laut lepas atau di Zona Ekonomi Eksklusif (ZEE) dengan hasil tangkapan berupa ikan pelagis besar, seperti ikan 
tuna. Sementara itu, nelayan Palabuhanratu umumnya menangkap ikan di sekitar Teluk Palabuhanratu dengan hasil tangkapan berupa ikan pelagis kecil dan demersal, seperti ikan layur dan ikan layang. Adapun ikan-ikan pelagis besar yang didaratkan di PPN Palabuhanratu berasal dari kapal nelayan pendatang yang wilayah penangkapannya di laut lepas.

Berdasarkan wilayah penangkapan tersebut, armada penangkapan yang digunakan nelayan di Bitung dan Palabuhanratu berbeda. Nelayan Bitung tercatat sebagian besar (35\%) menggunakan kapal yang berukuran > 30 GT dengan alat tangkap tuna hand line, purse seine, dan pole and line. Target utama tangkapan pole and line adalah ikan cakalang dan hand line adalah tuna. Sementara itu, sebagian besar (45\%) nelayan Palabuhanratu menggunakan kapal berukuran 5-10 GT dengan alat tangkap pancing, gillnet, dan long line. Bahkan, nelayan Palabuhanratu juga yang menggunakan alat bantu penangkapan berupa bagan dan rumpon yang diletakkan di sekitar Teluk Palabuhanratu untuk mengakomodir armada penangkapan yang tidak mampu menjangkau wilayah penangkapan yang lebih jauh.

\section{Kontribusi Biaya Solar Terhadap Biaya Operasional Penangkapan}

Ditinjau dari jenis armada penangkapan, nelayan Bitung dan Palabuhanratu sangat merasakan manfaat subsidi harga solar karena mereka sebagian besar menggunakan kapal motor yang berbahan bakar solar. Di Kota Bitung, teridentifikasi kapal penangkap yang menggunakan alat tangkap pole and line merupakan kapal yang menggunakan solar terbesar di Pelabuhan Perikanan Samudera (PPS) Bitung, yaitu 4,9 kiloliter per trip atau mampu menyerap $23 \%$ dari total penyaluran solar dari SPBB di PPS Bitung. Biaya untuk pembelian solar bagi kapal pole and line adalah $65 \%$ dari total biaya operasional.
Selain kapal penangkap ikan, kapal pengangkut ikan yang berlabuh di PPS Bitung juga mendapatkan solar bersubsidi yang disalurkan oleh SPBB Getra di PPS Bitung. Sebanyak $50 \%$ jumlah solar yang disalurkan oleh SPBB tersebut adalah untuk kapal pengangkut ikan. Sebanyak 50\% lagi disalurkan pada kapal penangkap dengan jenis alat tangkap rawai tuna, purse seine, dan hand line. Biaya untuk pembelian solar bagi kapal ikan dengan alat tangkap lainnya hanya sekitar $30 \%$ dari total biaya operasional.

Di Palabuhanratu, nelayan menggunakan berbagai jenis kapal maupun mesin yang berbahan bakar solar dan premium/bensin, sedangkan bahan bakar jenis kerosin/minyak tanah hanya digunakan untuk keperluan penerangan saja. Hingga tahun 2010, pihak Pelabuhan Perikanan Nusantara Palabuhanratu baru menyediakan BBM jenis solar saja yang digunakan untuk kapal perikanan yang berukuran > $10 \mathrm{GT}$, yakni kapal yang menggunakan mesin diesel untuk jenis kapal dogol, gillnet, longline dan kapal rumpon. Sedangkan jenis mesin tempel digunakan untuk kapal payang dan kincang dengan BBM jenis premium/bensin.

Kebutuhan solar nelayan Palabuhanratu skala usaha mikro dan kecil merupakan komponen yang sangat penting dalam menjalankan kegiatan penangkapannya. Hal ini karena komponen biaya BBM berkisar antara $40-60 \%$ dari seluruh biaya operasional penangkapan ikan. Akibatnya, bila terjadi kenaikan harga BBM jenis solar sebesar $28 \%$ maka akan menambah beban biaya produksi penangkapan ikan sebesar $28 \% \times 40 \%=11,2 \%$. Artinya, dengan kenaikan harga BBM solar tersebut maka nelayan mengalami beban tambahan yang harus dikeluarkan sebesar $11,2 \%$. Kondisi seperti ini sangat memberatkan nelayan, terlebih lagi karena selama ini nelayan dalam memenuhi kebutuhan BBM solar dibeli dari pihak ketiga (tengkulak) yang harganya lebih mahal kurang lebih 30\% dari harga ketentuan pemerintah. 


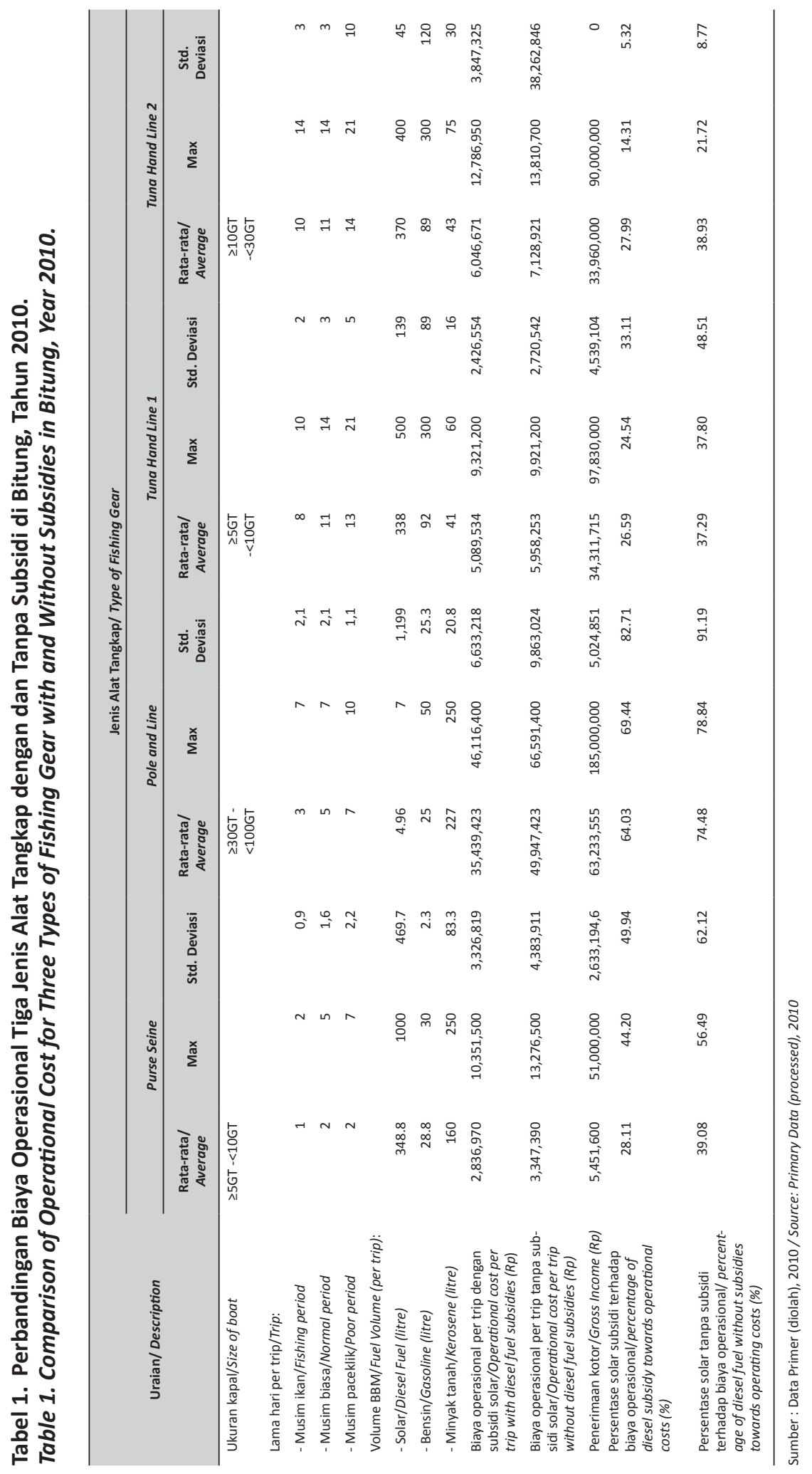




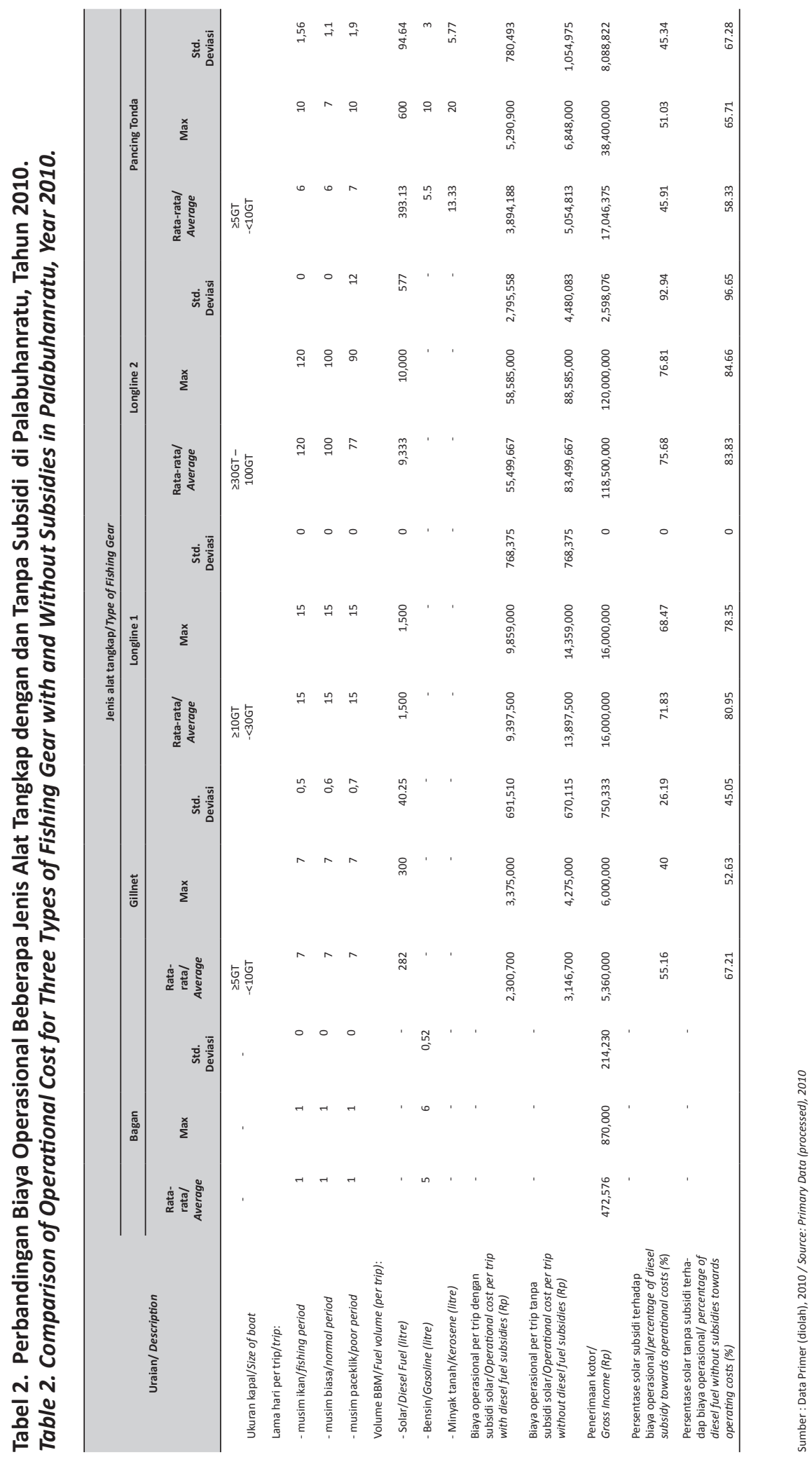


Peran atau pengaruh subsidi harga solar terhadap usaha penangkapan dapat dilihat dari perbandingan besarnya biaya operasional yang dikeluarkan nelayan apabila menggunakan solar bersubsidi dengan biaya operasional tanpa subsidi. Di Bitung dan Palabuhanratu, solar bersubsidi dengan harga Rp 4.500 per liter memberikan pengaruh yang signifikan terhadap total biaya operasional. Tanpa adanya subsidi solar (dengan asumsi harga solar Rp 7.500 per liter) menyebabkan peningkatan total biaya operasional bagi seluruh kapal penangkap ikan dengan kapal motor.

Pada tingkat harga solar Rp 7.500 per liter meningkatkan persentase biaya solar terhadap total biaya operasional berkisar $38-74 \%$ pada nelayan di Bitung. Total biaya operasional juga mengalami peningkatan sebesar $17-41 \%$ dibandingkan dengan pemakaian solar bersubsidi. Peningkatan biaya operasional tertinggi terjadi pada kapal dengan alat tangkap pole and line, yaitu $41 \%$ dibandingkan jika menggunakan solar bersubsidi. Biaya operasional kapal dengan alat tangkap tuna hand line mengalami peningkatan sebesar $18 \%$ dibandingkan jika menggunakan solar bersubsidi.

Tabel 1 menunjukkan bahwa kapal dengan konsumsi solar lebih banyak akan merasakan dampak yang lebih besar terhadap perubahan harga solar. Dampak yang sangat terlihat jelas pada besarnya biaya operasional per trip yang harus dikeluarkan oleh nelayan yang meningkat apabila menggunakan solar tanpa subsidi. Peningkatan biaya operasional tertinggi akan dialami oleh kapal dengan alat tangkap pole and line jika menggunakan solar tanpa subsidi, yaitu sebesar $41 \%$. Sementara itu, naiknya biaya operasional juga dialami oleh nelayan yang menggunakan kapal dengan alat tangkap purse seine dan tuna hand line (kapal ukuran $\geq 10-<30$ GT) yang masing-masing sebesar $18 \%$. Untuk kapal ukuran $\geq 5$ - < 10 GT dengan alat tangkap tuna hand line, biaya operasional akan meningkat sebesar $17 \%$ jika menggunakan solar tanpa subsidi.
Peningkatan biaya operasional dengan solar tanpa subsidi menyebabkan keuntungan yang diperoleh nelayan semakin rendah. Penurunan keuntungan nelayan untuk kapal dengan alat tangkap purse seine dengan solar tanpa subsidi adalah 20\% dibandingkan dengan menggunakan solar bersubsidi. Persentase penurunan keuntungan yang paling rendah dialami oleh nelayan yang menggunakan kapal dengan alat tangkap tuna hand line, baik yang berukuran $\geq 5-<10$ GT maupun ukuran $\geq 10$ - < 30 GT yang masing-masing sebesar 3\% dan $4 \%$ jika menggunakan solar tanpa subsidi.

Dari ketiga jenis alat tangkap yang digunakan, pemberian subsidi solar paling dirasakan dampaknya bagi nelayan dengan alat tangkap pole and line dengan ukuran $\geq 30$ GT - <100GT. Kenaikan biaya operasional ini berdampak pada turunnya keuntungan yang diperoleh nelayan rata-rata sebesar $52 \%$. Hasil ini menunjukkan bahwa semakin besar ukuran kapal yang memerlukan solar lebih banyak maka manfaat subsidi solar semakin dirasakan oleh nelayan.

Hal yang sama juga terjadi pada nelayan Palabuhanratu yang merasakan manfaat dari subsidi harga solar. Tanpa menggunakan solar bersubsidi pada tingkat harga Rp 7.500, total biaya operasional nelayan meningkat 30-50\% dibandingkan apabila nelayan menggunakan solar bersubsidi. Akibatnya, prosentase biaya solar terhadap total biaya operasional juga meningkat sebesar $13-27 \%$. Peningkatan biaya operasional tertinggi terjadi pada kapal dengan alat tangkap longline, yaitu sebesar $50 \%$, sedangkan peningkatan terendah sebesar $30 \%$ terjadi pada kapal dengan alat tangkap pancing tonda dibandingkan jika menggunakan solar bersubsidi.

Tabel 2 menunjukkan bahwa kapal dengan ukuran lebih besar sangat merasakan dampak pemberian subsidi harga solar karena konsumsi solarnya jauh lebih banyak dibandingkan dengan kapal ukuran lebih kecil. Artinya, nelayan Palabuhanratu yang 
menggunakan kapal dengan alat tangkap longline yang paling besar merasakan manfaat subsidi harga solar karena ukuran kapalnya ( $\geq 10 G T-100 \mathrm{GT}$ ) jauh lebih besar dibandingkan kapal gillnet dan pancing tonda ( $\geq 5 \mathrm{GT}-<10 \mathrm{GT}$ ).

Peningkatan biaya operasional dengan solar tanpa subsidi menyebabkan keuntungan yang diperoleh nelayan semakin rendah. Penurunan keuntungan nelayan untuk kapal dengan alat tangkap gillnet dengan solar tanpa subsidi adalah $28 \%$ dibandingkan dengan menggunakan solar bersubsidi. Persentase penurunan keuntungan yang paling rendah dialami oleh nelayan yang menggunakan kapal dengan alat tangkap pancing tonda, yaitu $9 \%$ jika menggunakan solar tanpa subsidi.

Dari keempat jenis alat tangkap yang digunakan, pemberian subsidi harga solar paling dirasakan dampaknya bagi nelayan dengan alat tangkap longline, terutama bagi kapal longline ukuran $\geq 10 \mathrm{GT}$ - <30GT. Kenaikan biaya operasional ini berdampak pada turunnya keuntungan yang diperoleh nelayan rata-rata sebesar 68 persen. Begitupula halnya dengan kapal longline ukuran $\geq 30$ GT - 100 GT yang harus mengeluarkan biaya operasional per trip lebih besar 50\% apabila menggunakan solar tanpa subsidi sehingga porsi biaya solar terhadap biaya operasional naik dari $76 \%$ menjadi $84 \%$. Dampak selanjutnya adalah menurunnya keuntungan yang diperoleh nelayan sebesar $44 \%$.

\section{Peran Subsidi Harga Solar Terhadap Keberlanjutan Usaha}

Hasil analisis OLS untuk lokasi Bitung dengan jumlah responden sebanyak 35 orang dimana variabel independent yang digunakan (Ln hari melaut, Ln ABK, Ln biaya operasional, dan dummy) dapat menjelaskan variabel dependent (Ln penerimaan) sebesar $86,6 \%$ dan sisanya dijelaskan oleh faktorfaktor lain. Ditinjau dari P-value dengan tingkat kepercayaan (significance level $-\alpha$ ) sebesar $5 \%$, variabel yang berpengaruh signifikan adalah biaya operasional dan variabel dummy (Tabel 3).

Variabel jumlah hari melaut per trip, jumlah $A B K$, dan biaya operasional berpengaruh positif terhadap penerimaan, dimana ada peningkatan variabel tersebut, maka penerimaan akan mengalami peningkatan sebesar koefisien masing-masing variabel tersebut. Dari hasil regresi tersebut model yang diperoleh adalah:

$$
\begin{array}{llll}
\text { LN Penerimaan }= & 8,87+\mathbf{0 , 1 1} \mathrm{LN} \text { Hari melaut }+\mathbf{0 , 0 3} \mathrm{LN} \mathrm{ABK}+\mathbf{0 , 4 1} \mathrm{LN} \text { BOP + 1,47 D } \\
\text { t-statistik } & (5,17)(0,70) & (0,14) & (2,70)
\end{array}
$$

Tabel 3. Koefisien, Varian dan P-value Variabel yang Mempengaruhi Ln Penerimaan di Bitung, Tahun 2010.

Table 3. Coefficient, Variance and P-value Variabel Which Influence Ln Revenue in Bitung, Year 2010.

\begin{tabular}{lccc}
\hline Variabel/Variable & $\begin{array}{c}\text { Nilai Koefisien/ } \\
\text { Coefficient Value }\end{array}$ & Nilai T/T-Value & $\begin{array}{c}\text { Nilai P/ } \\
\text { P-Value }\end{array}$ \\
\hline Konstanta/Constanta & 8.87 & 5.17 & 0.000 \\
Ln Hari melaut & 0.11 & 0.70 & 0.490 \\
Ln ABK & 0.03 & 0.14 & 0.893 \\
Ln Biaya operasional & 0.41 & 2.70 & 0.011 \\
Dummy & 1.47 & 4.09 & 0.000 \\
$\mathrm{R}^{2}$-adjusted & 0.866 & & \\
\hline
\end{tabular}

Sumber: Output OLS, 2010/ Source : Output OLS, 2010 
Variabel dummy digunakan untuk mengetahui pengaruh subsidi terhadap Ln penerimaan, dalam hal ini merupakan salah satu variabel dari keberlanjutan usaha perikanan tangkap. Subsidi untuk nelayan di Bitung yang dimaksud adalah subsidi terhadap bahan bakar solar dengan adanya kebijakan pemerintah membangun sarana pengisian bahan bakar solar di pelabuhan perikanan. Dummy 1 untuk nelayan yang menggunakan mesin dengan bahan bakar solar yang dapat diperoleh dengan harga subsidi, yaitu Rp4.575 per liter. Dummy 0 untuk nelayan atau responden yang menggunakan armada penangkapan dengan perahu motor tempel yang menggunakan bensin dan minyak tanah sebagai bahan bakar utama. Walaupun bensin masih disubsidi oleh pemerintah di SPBU, tetapi nelayan tidak dapat melakukan pembelian dengan mudah sehingga untuk mendapatkan bensin sesuai dengan kebutuhan maka nelayan harus mengeluarkan biaya tambahan.

Penelitian ini mengelompokkan responden yang tidak menggunakan bahan bakar solar sebagai kelompok nelayan yang tidak mendapat subsidi. Besarnya pengaruh subsidi terhadap Ln penerimaan tidak dapat dikatakan sebesar koefisien yang dihasilkan dari OLS, tetapi terlebih dahulu dilakukan suatu analisis yang dikemukakan Kennedy (1981). Hasil analisis OLS semilogarithmic yang dilakukan menunjukkan bahwa variabel dummy ini berpengaruh signifikan terhadap Ln penerimaan sebesar 2,88. Hal ini dapat dijelaskan bahwa pemberian subsidi solar kepada nelayan dapat meningkatkan penerimaan sebesar $2,88 \%$ sehingga dapat disimpulkan bahwa dengan adanya subsidi solar maka usaha perikanan tangkap yang dilakukan oleh nelayan di Bitung dapat dilakukan secara berkelanjutan.

Sementara itu, analisis OLS juga dilakukan untuk lokasi Palabuhanratu dengan 35 responden yang terdiri dari nelayan dengan menggunakan alat tangkap bagan, gillnet, pancing tonda, dan longline. Seluruh alat tangkap gillnet dan sebagian alat tangkap pancing tonda dioperasikan dalam Teluk Palabuhanratu. Alat tangkap longline dan sebagian alat tangkap pancing tonda dioperasikan pada wilayah penangkapan yang lebih jauh, bahkan untuk alat tangkap longline dioperasikan sampai ke laut lepas di perbatasan Indonesia dengan Australia.

Hasil regresi di atas menunjukkan bahwa seluruh variabel penjelas berpengaruh signifikan terhadap Ln penerimaan, kecuali variabel $L n A B K$ dan model yang dihasilkan adalah:

$$
\begin{aligned}
& \mathrm{LN} \text { Penerimaan }=-6,80-1,13 \mathrm{LN} \text { Hari melaut }+0,07 \mathrm{LN} \mathrm{ABK}+1,85 \mathrm{LN} \text { BOP }-2,80 \mathrm{D} \\
& \text { t-statistik } \\
& (-2,20)(-3,66)
\end{aligned}
$$

Tabel 4. Koefisien dan Varian Variabel yang Mempengaruhi Ln Penerimaan di Palabuhanratu, Tahun 2010.

Table 4. Coefficient and VarianceVariable Which Influence Ln Revenue in Palabuhanratu, Year 2010.

\begin{tabular}{lccc}
\hline \multicolumn{1}{c}{ Variabel/Variable } & $\begin{array}{c}\text { Nilai Koefisien/ } \\
\text { Coefficient Value }\end{array}$ & Nilai T/T-Value & Nilai P/P-value \\
\hline Konstanta/Constanta & -6.80 & -2.20 & 0.035 \\
Ln Hari melaut & -1.13 & -3.66 & 0.001 \\
Ln ABK & 0.07 & 0.32 & 0.750 \\
Ln Biaya operasional & 1.85 & 6.40 & 0.000 \\
Dummy & -2.80 & -3.45 & 0.001 \\
$\mathrm{R}^{2}$-adjusted & 0.924 & & \\
\hline
\end{tabular}

Sumber: Output OLS, 2010/Source : Output OLS, 2010 
Variabel Ln jumlah hari melaut dan dummy berpengaruh negatif terhadap penerimaan. Variabel Ln jumlah hari melaut memiliki nilai koefisien negatif yang berarti bahwa peningkatan jumlah hari melaut menyebabkan penurunan jumlah penerimaan dari usaha penangkapan ikan di Palabuhanratu. Secara teori, penambahan jumlah effort seperti jumlah hari melaut dalam usaha perikanan tangkap akan meningkatkan penerimaan nelayan. Hasil ini menunjukkan bahwa pemanfaatan sumber daya perikanan di Teluk Palabuhanratu telah adanya indikasi kelebihan upaya penangkapan.

Variabel dummy bernilai koefisien negatif yang berarti bahwa adanya penambahan pemberian subsidi bahan bakar solar akan mengurangi penerimaan dari usaha perikanan tangkap di Palabuhanratu. Hasil regresi menunjukkan bahwa apabila variabel dummy bernilai 1 satuan maka penerimaan akan berkurang sebesar 0,94 satuan, ceteris paribus.

\section{KESIMPULAN DAN IMPLIKASI KEBIJAKAN}

\section{Kesimpulan}

Hasil penelitian menunjukkan bahwa biaya pembelian solar menjadi komponen terbesar dari total biaya operasional per trip penangkapan yang harus dikeluarkan nelayan sehingga naiknya harga bahan bakar minyak (BBM) dalam tahun-tahun belakangan ini sangat memberatkan nelayan dalam melakukan kegiatan penangkapan. Berdasarkan hasil penelitian yang dilakukan di Bitung dan Palabuhanratu, intervensi pemerintah melalui pemberian subsidi harga solar masih sangat diperlukan oleh nelayan dalam negeri untuk menjamin keberlanjutan usaha penangkapannya. Pihak yang sangat berperan dalam memberikan pelayanan bahan bakar solar dengan harga subsidi adalah Pelabuhan Perikanan Samudera Bitung dan Pelabuhan Perikanan Nusantara Palabuhanratu, baik secara langsung melalui milik pelabuhan perikanan maupun tidak langsung melalui pihak swasta yang telah bekerja sama dengan pelabuhan perikanan.
Salah satu variabel yang dapat menunjukkan keberlanjutan usaha perikanan tangkap adalah penerimaan yang diperoleh nelayan per trip penangkapan. Variabel penerimaan tersebut dipengaruhi oleh variabel jumlah hari melaut, jumlah $A B K$, biaya operasional per trip, dan dummy. Variabel dummy (D) merupakan variabel yang menjelaskan pemberian subsidi BBM pada nelayan yang menggunakan bahan bakar solar ( $D=1$ adanya subsidi harga solar, $D=$ 0 tanpa subsidi harga solar).

Hasil analisis OLS untuk lokasi Bitung menunjukkan bahwa variabel bebas yang digunakan (Ln hari melaut, Ln ABK, Ln biaya operasional, dan dummy) dapat menjelaskan variabel tidak bebas (Ln penerimaan) sebesar $88,2 \%$. Ditinjau dari P-value, variabel yang berpengaruh signifikan adalah biaya operasional dan variabel dummy. Variabel dummy berpengaruh signifikan terhadap Ln penerimaan sebesar 2,88 sehingga dapat dijelaskan bahwa pemberian subsidi solar kepada nelayan dapat meningkatkan penerimaan sebesar 2,88\%. Dengan demikian, dapat disimpulkan bahwa dengan adanya subsidi solar maka usaha perikanan tangkap nelayan di Bitung dapat dilakukan secara berkelanjutan.

Hasil analisis OLS yang dilakukan di Palabuhanratu menunjukkan bahwa seluruh variabel penjelas berpengaruh signifikan terhadap Ln penerimaan, kecuali variabel Ln ABK. Variabel Ln hari melaut dan dummy berpengaruh negatif terhadap penerimaan. Hasil regresi ini menjelaskan bahwa adanya penambahan jumlah effort seperti jumlah hari melaut justru akan menurunkan penerimaan nelayan Palabuhanratu. Hasil ini menjelaskan bahwa pemanfaatan sumber daya perikanan di Teluk Palabuhanratu telah adanya indikasi kelebihan upaya penangkapan.

Pemberian subsidi harga solar yang diwakili oleh variabel dummy juga menunjukkan hasil yang sama. Variabel dummy berpengaruh signifikan terhadap Ln penerimaan sebesar minus 0,94 sehingga dapat dijelaskan bahwa pemberian subsidi solar kepada nelayan dapat 
menurunkan penerimaan sebesar 0,94\%. Dengan demikian, dapat disimpulkan bahwa usaha perikanan tangkap di Palabuhanratu tidak dapat dilakukan secara berkelanjutan dengan adanya pemberian subsidi harga solar karena adanya penambahan pemberian subsidi bahan bakar solar justru mengurangi penerimaan dari usaha perikanan tangkap di Palabuhanratu. Untuk itu, perlu dikomplemen dengan perbaikan kapasitas produksi perikanan tangkap.

\section{Implikasi Kebijakan}

Adanya penambahan effort yang menyebabkan semakin rendahnya keuntungan dari usaha perikanan menunjukkan suatu indikasi bahwa usaha perikanan tangkap di Bitung yang dilakukan pada wilayah penangkapan Laut Sulawesi dan Maluku telah mengalami kejenuhan. Beberapa hal yang mungkin terjadi adalah telah terjadi kelebihan tangkapan untuk spesies cakalang, adanya kelebihan upaya penangkapan pada wilayah penangkapan yang sama, dan terdegradasinya spesies cakalang. Untuk itu, perlu adanya skema pengelolaan yang tepat dalam pemanfaatan sumber daya ikan cakalang pada wilayah penangkapan tersebut.

Untuk lokasi Palabuhanratu, perlu ditinjau kembali pemberian subsidi kepada nelayan yang melakukan penangkapan ikan menggunakan alat tangkap bagan, gillnet, dan pancing tonda yang melakukan penangkapan di Teluk Palabuhanratu. Di samping itu, perlu adanya perubahan armada penangkapan bagi nelayan sehingga nelayan dapat melakukan penangkapan ikan pada fishing ground yang lebih jauh, seperti ZEE dan laut lepas sebelah selatan Indonesia untuk mengurangi tekanan penangkapan ikan di wilayah penangkapan (fishing ground) Teluk Palabuhanratu. Apabila nelayan terus melakukan penangkapan ikan di Teluk Palabuhanratu maka usaha perikanan tangkap tersebut tidak dapat dilakukan secara berkelanjutan dan juga sumber daya yang ada terancam punah.

\section{DAFTAR PUSTAKA}

Anonim. 2010. Oxford English Dictionary (OED). London: Oxford University Press.

Ginanjar. 2010. Nelayan Sambut Subsidi Perikanan. http://www.dkp.go.id/ archives/c/58/3455/- nelayan -sambutsubsidi-perikanan/. Diakses tanggal 3 November 2010.

Kennedy, P.E. 1981. Estimation With Correctly Interpreted Dummy Variables In Semilogarithmic Equation. The American Economic Review. 71 (4): 801

Milazzo, M. 1998. Subsidies in world fisheries a re-examination. World Bank Technical Paper No. 406. The International Bank for Reconstruction and Development/ World Bank, Washington. 86p.

Pindyck, R.S. and D.L. Rubinfield. 1998. Econometric Models and Economic Forecast, Fourth Edition. Singapura: McGraw Hill Book Co-Singapore. 634p.

Satria, A, Anggraini E. dan A. Solihin. 2009. Globalisasi Perikanan: Reposisi Indonesia? Bogor: IPB Press. 123p.

Schrank, W.E., and W.R. Keithly Jr. 1999. Thalassorama - The concept of subsidies. Marine Resource Economics, XIV:151-164.

WTO. 2006. WTO Report: Subsidies, Trade and The WTO. WTO Secretariat. 180p.

Zulham, A. 2008. Dampak Subsidi Terhadap Surplus Produsen dan Total Benefit Perikanan Tangkap Pantura Jawa Tengah. J. Bijak dan Riset Sosek KP. 3 (1) 1-12. 